given on the fine structure of the cuticle and other parts. Zoologists and parasitologists alike will be delighted by information and ideas here consolidated. Without the complete coverage here afforded any attempts to deal with the affinities of the Nemathelminthes (Aschelminthes) are futile. This topic is treated adequately, various theories are mentioned and the arguments of protagonists of the theory that the nematodes are derived from arthropods are stated fully but reasons are given for their derivation from Dalyellian Turbellaria. It is shown that the various classes considered have such affinities as merit their grouping as Aschelminthes and it is suggested that paedomorphosis (neoteny), which has sometimes been held to account for the relative simplicity of nematode structure, has played an important part in giving origin to the various groups.

BEN DAWES

\section{GRAFTS FOR MAN}

\section{Histocompatibility Testing}

Report of a Conference and Workshop sponsored by the Division of Medical Sciences, National Academy of Sciences, National Research Council, 7-12 June, 1964. (Publication 1229.) Pp. 192. (Washington: National Academy of Sciences-National Research Council, 1965.) $\$ 6.00$.

\section{The Biology of Tissue Transplantation}

By Paul S. Russell and Anthony P. Monaco. (New England Journal of Medicine Medical Progress Series.) Pp. viii +207 . (Boston, Mass.: Little, Brown and Company, 1965.) $\$ 6.75$.

If the transplantation of tissues and organs between one human being and another is to become a routine surgical procedure, then the graft donor must be chosen so that he has as many antigens as possible in common with the prospective recipient and possesses as few antigens as possible which are absent in the recipient. To make such matching possible, methods must be sought to determine what antigens are present on human cells. Histocompatibility Testing is a testimony to the amount of research at present being done in this field and to the ingenuity of the workers concerned. The first part of the report is devoted to the results of the various contributors trying to "type" or antigenically analyse cells in vivo and in vitro. This section is so well summarized by $\mathrm{H}$. Sherwood Lawrence that an attempt to do so in this review would be superfluous. The second part of the report is devoted to the description and practical details of the tests used to obtain the results presented earlier. Most authors have made a valuable contribution to this section, describing their tests in detail, together with possible pitfalls. There are, however, certain annoying deficiencies which could easily have been avoided. Some authors have sacrificed clarity for brevity; others do not always quote the exact concentrations of reagents; one author almost completely neglects to describe his test at all; yet another describes a standardization procedure which he certainly could not carry out himself (nor, it might be added, could anyone else). However, this book does provide, for those interested in tissue typing, a good progress report.

The Biology of Tissue Transplantation, by two surgeons who practise both applied and experimental tissue transplantation, represents an up-to-date review of the field of transplantation immunology. As such it is of interest both to the surgeon and to the experimental biologist and deserves to be read by both. The authors have presented both the old-established facts and present research trends in a readable form. The sections on the nature of the homograft reaction, the alteration of the immunological reactivity of the graft recipient, and the clinical aspects of transplantation are excellent. On the other hand, transplantation antigens deserved to be treated much more critically. The one general criticism of an otherwise excellent book is that the authors have been a little too prone on occasions to take at face value some of the claims made in the literature quoted. As some 600 references are cited, this is perhaps, to a certain extent, understandable.

G. Gowland

\section{REMARKABLE AND FEARSOME}

\section{Foundations of Anesthesiology}

By Albert Faulconer and Thomas E. Keys. Vol. 1: Pp. 1+1-716. Vol. 2: Pp. 1+717-1337. (Springfield, Ill.: Charles C. Thomas, 1965.) $\$ 38.50$.

Anaesthesia is one of the fastest growing fields of modern medicine. This is true not only of its technology, but of the understanding of the fundamental processes which it involves both at the level of the organ and at that of the cell. It is natural that amidst the welter of new knowledge, the origins of the old on which the new is built might be overlooked or even misunderstood. Sometimes the full implication of new observations is not realized through lack of care in reading the original accounts of earlier experiments, and much time and effort may thereby be needlessly wasted. Albert Faulconer, an anaesthesiologist in the Mayo Clinic, has joined forces with Thomas Keys, a librarian and historian particularly interested in anaesthesia, to gather together a large series of papers which they rightly consider to be the foundation stones of modern anaesthetic practice and understanding. Their volumes will both educate and make humble any anaesthetist who reads them and they will provide a long lasting source of information for any physician or biologist interested in this field. They make clear that while modern technology is of great importance in anaesthetic research, essentially intellectual processes of reasoning count for as much, and were particularly important when deductions were made from data which were often obtained with the simplest of equipment.

The 150 papers which are collected in these two volumes cover most of the wide range of the anaesthetic field. The majority would be difficult to find in the original, and many are translated into English for the first time.

Almost any page opened at random produces a gem. What better example than this quotation from Sir Hum. phry Davy in 1800, "Supposing that no part of the water evolved in solution by the expired gas of common air is formed immediately in respiration, it will follow that a very considerable quantity of oxygene must be constantly combined with the red particles, even allowing the consumption of a certain portion of it to form carbonic acid; for the carbonic acid evolved, rarely amounts to more than three fourths of the volume of the oxygene consumed", or this from Flourens in 1847, when ether was being increasingly used, mostly by completely unqualified people who regarded it as an innocuous substance: "When the surgeon contemplates the possibility of the use of ether in an operation, the prime consideration must also be borne in mind: ether which possesses the power to abolish pain can also endanger life. Henco the new agent which has just been added to the resources of surgery is at once remarkable and fearsome." This statement is as true to-day of the wide range of anaesthetic drugs now available as it was then of ether, and is the basic reason why anaesthesia has become such a highly developed specialty within the general field of medicine. Many of the papers in these volumes could be regarded as of historical importance only but others are of quite immediate importance.

These books will provide good reading, intellectual delight, and scientific education for as long as they are possessed, for their contents will never age.

W. W. Mushin 